\title{
Shear strength characteristics of shotcrete-rock interface for a tunnel driven in high rock temperature environment
}

\author{
Jianjun Tong $\cdot$ Murat Karakus $\cdot$ Mingnian Wang $\cdot$ \\ Congyu Dong $\cdot$ Xinghua Tang
}

Received: 25 July 2016/Accepted: 11 September 2016/Published online: 19 September 2016

(C) Springer International Publishing Switzerland 2016

\begin{abstract}
The shear behavior of shotcrete-rock interface same as the bond behavior plays a significant role on shotcrete behaviour in a tunnel. The shear strength of shotcrete-rock interface is noticeably affected by high temperature in high rock temperature tunnels. However, there are limited number of studies dedicated to investigate behaviour of shotcrete-rock interface in high temperatures. Therefore, a series of direct shear tests was performed, under the normal stress of $0.5,1.0$ or $1.5 \mathrm{MPa}$, to investigate the influence of high rock temperature on the shear characteristics of shotcrete-rock interface. Shotcrete-rock samples were cured under the temperature range of 20 to $100{ }^{\circ} \mathrm{C}$ and the relative humidity of 55 or $95 \%$ before shear tests. The results show that curing temperature, relative humidity and normal stress have significant impacts on the peak shear strength, however, only the normal stress has the same impact on the residual shear strength. The peak shear
\end{abstract}

J. Tong · M. Karakus ( $\square)$

School of Civil, Environmental and Mining Engineering, University of Adelaide, Adelaide, SA 5005, Australia

e-mail: murat.karakus@adelaide.edu.au

J. Tong $\cdot$ M. Wang $\cdot$ C. Dong $\cdot$ X. Tang

Key Laboratory of Transportation Tunnel Engineering,

Ministry of Education, School of Civil Engineering,

Southwest Jiaotong University,

Chengdu 610031, Sichuan, China

e-mail: 19910622@163.com strength as well as peak cohesion reaches its maximum value at $60{ }^{\circ} \mathrm{C}$ curing temperature with $55 \%$ relative humidity level, and at $80{ }^{\circ} \mathrm{C}$ curing temperature when the relative humidity is $95 \%$. The shear stressdisplacement curve presents various shapes in the section of post-shear due to the influence of high temperature and relative humidity.

Keywords Shear strength - High rock temperature tunnel $\cdot$ Shotcrete-rock interface $\cdot$ Curing temperature $\cdot$ Curing relative humidity

\section{Introduction}

If the rock temperature is above $30{ }^{\circ} \mathrm{C}$, this condition is generally recognized as high rock temperature. The causes of high rock temperature are mainly the depth of tunnel, activity of magma or hot groundwater and age of formation. The number of high rock temperature tunnels constructed in the world is increasing recently (Wilhelm and Rybach 2003; Hochstein and Prebble 2006; Hou et al. 2013; Xie and Yu 2013; Gu 2015). Some researchers have found that mechanical properties of tunnel lining (shotcrete) are affected by high rock temperature (Paul and Glasser 2000; Liu et al. 2001; Wang et al. 2015). Due to key role that shotcrete plays in tunnel support system, the mechanical behavior of interface between shotcrete and rock needs to be investigated thoroughly for a safer design. 
Many researchers have been focused on the shear behavior of interfaces with or without infill material between rock and shotcrete at normal temperature (For example Karakus et al. 2016; Zhang et al. 2014). For unbounded interface, it was demonstrated that the peak angle of friction was dependent on both normal stiffness and initial normal stress while the residual angle of friction is essentially independent (Johnston and Lam 1984). Large direct shear tests of regular triangular concrete-rock joints for conditions of both constant normal stiffness and constant normal load were performed to prove that the analytical approaches are capable of describing the stress variations and displacements at the interface (Lam and Johnston 1989). Under conditions of constant normal stiffness and constant normal load, failure of both regular and irregular joints were accompanied by shearing and crushing of the rock asperities. However, the irregular joints showed a much greater relative ductility than the regular joints (Kodikara and Johnston 1994). Laboratory tests of concrete-rock joints in constant normal stiffness in direct shear test demonstrated that the joint performance was highly dependent on surface roughness profiles (Seidel and Haberfield 2002). Gu et al. (2003) investigated the wear of the sandstone surface during direct shear test and showed the significant effects of roughness profiles on the behavior of the sandstone-concrete joints.

For bonded interface, it was found that the peak and residual strength envelopes were independent of the initial normal stress and the normal stiffness during shearing and bonding of the concrete to the sandstone improved the peak and residual strength but decreased the rate of post peak softening (Ooi and Carter 1987). Bae et al. (2004) conducted many shear test experiments and results of their study revealed that interface properties between rock and shotcrete showed a significant time-dependent variation similar to those of its mechanical properties. An exponential and a logarithmic functions were proposed for the timedependent behaviors of rock-concrete interface. Shear strength is determined by the bond strength for bonded shotcrete-rock interfaces under lower normal stress (0.2-0.5 MPa), but largely influenced by friction under higher normal stress (>1.0 MPa) (Saiang et al. 2005). The similar shear behaviors were also observed by Tian et al. (2015).

On the other hand, the numerical simulation is very useful to describe the shear behavior between concrete and rock, such as PFC2D (Tannant and Wang 2004; Karakus et al. 2016), UDEC (Malmgren and Nordlund 2008). However, there are little literature on the shear strength properties of concrete-rock or shotcrete-rock interfaces at high temperature level. The research focus was mostly on the bond strength of concreterock interfaces at a range of curing temperature and humidity using tensile test and splitting test. Ou (2011) investigated 7-day splitting strengths of shotcreterock samples at various temperature levels which were cured at 20,35 or $50{ }^{\circ} \mathrm{C}$. Experiments on wet-sprayed shotcrete specimens under different curing temperatures and humidity conditions $\left(35,50,70{ }^{\circ} \mathrm{C}\right.$, and standard curing conditions: $20^{\circ} \mathrm{C}$ with relative humidity $95 \%$ ) were performed. The bond strength at $35^{\circ} \mathrm{C}$ is found to be higher compared to that of the ones at standard curing conditions and it decreases when the temperature rises (especially at $70{ }^{\circ} \mathrm{C}$ ), indicating the adverse effects of thermal damage on the bond strength (Cui et al. 2015). The bonding strength between shotcrete and rock dropped with the increasing of temperature in the range of 50 to $90{ }^{\circ} \mathrm{C}$ in the condition of $90 \%$ relative humidity (Ma et al. 2015).

Therefore, in order to evaluate the shear properties of shotcrete-rock interfaces in high rock temperature tunnel, a series of laboratory experiments were conducted and the influences from curing temperature, relative humidity and normal stress were analyzed.

\section{Experimental methodology}

\subsection{Specimen preparation}

The specimen is composed of shotcrete and granite. Geometry of the shotcrete and granite is shown in Fig. 1.

Firstly rectangular granite prism is cut and put into a mold. Then shotcrete is poured onto granite as shown in Fig. 1. The granite specimens were collected from Mountain Emei, China. Mineralogical composition and structure of the granites are as pleocrystalline, medium grained and homogenous texture, massive structure, composed of $40 \%$ quartz, $45 \%$ plagioclase, $10 \%$ black mica and $5 \%$ hornblende. Grain sizes are in the range of $2-5 \mathrm{~mm}$. The physical and mechanical parameters of granite are summarized in Table 1. As can be seen from Fig. 1, sides and the 


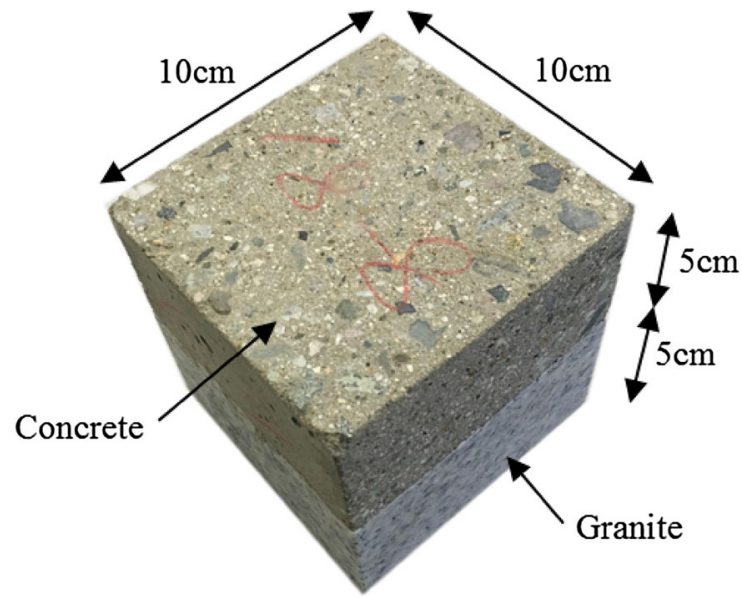

Fig. 1 Shotcrete-granite sample for interface test

bottom of the granite surfaces are smooth whereas interface surface of the granite is rough with 0-2 JRC value (Zhang et al. 2014).

\subsection{Shotcrete properties}

The kinds of shotcrete used in the tests are C25 and C30, whose mix proportions were referred to the typical high rock temperature tunnel named Ji Wo Xi Ga in Lhasa-Shigatse railway, China (Table 2). The strength grade of ordinary Portland cement was 42.5 (AQSIQ and SA, 2007). The diameter of sand was in the range of $0.5-0.35 \mathrm{~mm}$ and the fineness modulus of sand was 2.54. The diameter of gravel was in the range of 5-10 mm. Strengths of the shotcrete C25 and C30 at 1-day curing are greater than $8 \mathrm{MPa}$ while strengths of the shotcrete $\mathrm{C} 25$ and $\mathrm{C} 30$ at 28-day curing are greater than $20 \mathrm{MPa}$ according to the standard for shotcrete (MHURD, 2015).

\subsection{Curing of specimen and shear test apparatus}

To reflect the real influence of high rock temperature on shotcrete-rock interface, the specimen curing condition must be in accordance with the condition at which shotcrete is applied in high rock temperature tunnel.

After excavation of high rock temperature tunnel, the hot rock or groundwater release heat and make the air temperature higher than normal conditions for workers and machinery. Therefore, some engineering measures are implemented to lower the ambient temperature; such as ventilation, spaying fog and sprinkling water, placing ice blocks in front of excavation face. The shotcrete sprayed also experiences this cooling process with the air in tunnel. According to the research findings of Ji Wo Xi Ga tunnel (Wang et al. 2016), shotcrete temperature will rapidly drop from initial rock temperature to air temperature in tunnel (usually $\sim 28^{\circ} \mathrm{C}$ ) in the first 5 days after sprayed, and remains constant thereafter. In order to be consistent with the curing time used in the lab, we also observed temperature changes over 28 days and called as Variable Temperature Curing (VTC) (Fig. 2).

Figure 3 shows the thermostat-humidistat device (HX/HS-010L) for specimen curing, which can provide the constant condition with the temperature of $0-100{ }^{\circ} \mathrm{C}$ and the relative humidity of $30-98 \%$. There is a cubic workroom of $1000 \mathrm{~mm}$ on each edge inside the device that can contain the large concrete member or be divided to three layers for more small specimens. After putting the specimen into the thermostat-humidistat device, the device is set up to the initial curing temperature and constant curing relative humidity. In the first 5 days, curing temperature decreases with same rate per $8 \mathrm{~h}$ and reaches $28{ }^{\circ} \mathrm{C}$ on the 5th day. During the period of the 6th to 28 th day, curing temperature is kept constant as $28^{\circ} \mathrm{C}$.

As a comparison, another curing method, Standard Curing (SC), was performed in the test, which is required in the code for concrete test method (MHURD, 2003). In SC, curing temperature and relative humidity are always constant during 28 days. Based on the field conditions of the rock temperature tunnels all over the world, parameters given in Table 3

Table 1 Physical and mechanical parameters of granite

\begin{tabular}{llllll}
\hline Density, $\rho\left(\mathrm{kg} / \mathrm{m}^{3}\right)$ & Elastic modulus, E $(\mathrm{GPa})$ & Poisson ratio, $v$ & Cohesion, c $(\mathrm{MPa})$ & Friction angle, $\phi\left({ }^{\circ}\right)$ & $\mathrm{UCS}, \sigma_{\mathrm{c}}(\mathrm{MPa})$ \\
\hline 2590 & 35.75 & 0.28 & 3.63 & 20.3 & 61.83 \\
\hline
\end{tabular}


Table 2 Mixing proportions of shotcrete

\begin{tabular}{|c|c|c|c|c|c|c|c|}
\hline \multirow[t]{2}{*}{ Shotcrete type } & \multirow[t]{2}{*}{$\mathrm{W} / \mathrm{C}$} & \multicolumn{4}{|c|}{ Amount of mix $\left(\mathrm{kg} / \mathrm{m}^{3}\right)$} & \multirow{2}{*}{$\begin{array}{l}\text { Accelerator for } \\
\text { hardening }(\%)\end{array}$} & \multirow{2}{*}{$\begin{array}{l}\text { Water } \\
\text { Reducer }(\%)\end{array}$} \\
\hline & & Cement & Water & Sand & Gravel & & \\
\hline $\mathrm{C} 25$ & 0.49 & 436.53 & 213.9 & 949.79 & 949.79 & 4 & 1 \\
\hline $\mathrm{C} 30$ & 0.45 & 442 & 200 & 949 & 987 & 4 & 1 \\
\hline
\end{tabular}

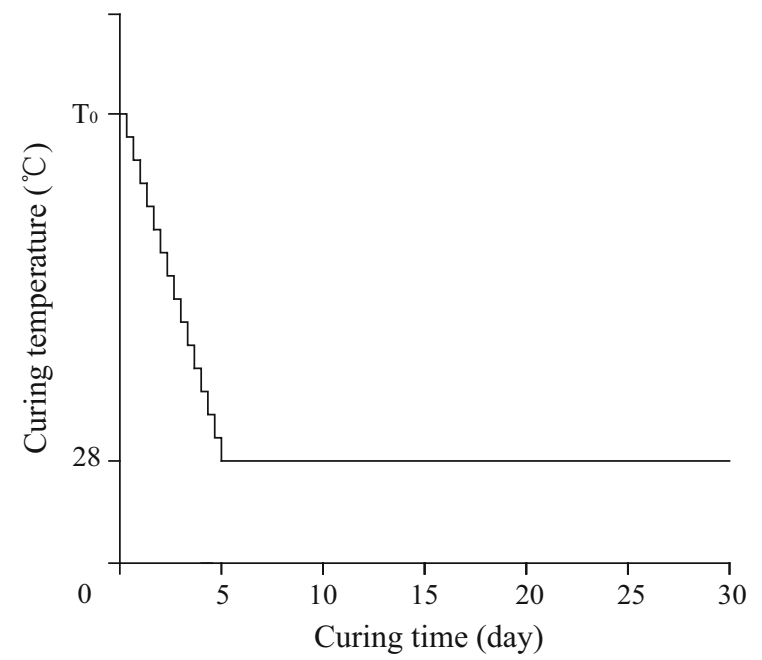

Fig. 2 Relationship between curing temperature and curing time (Note $\mathrm{T}_{0}$ is the initial curing temperature)

were chosen to use in tests for the shear behavior of the shotcrete-rock interfaces.

The direct shear tests were conducted on multifunctional testing machine (YDS-2 system), shown in Fig. 4. The maximum normal and shear forces from load jacks are $600 \mathrm{kN}$ and $300 \mathrm{KN}$ respectively. The data acquisition system includes 4 normal displacement sensors, 2 horizontal displacement sensors, 1 normal force sensor and 1 shear force sensor. The shear stress was applied at a rate of $0.1 \mathrm{kN} / \mathrm{s}$. Both normal and shear displacements and stresses were simultaneously recorded.

\subsection{Failure face}

Four typical kinds of shear failure at the shotcrete-rock interface are presented in Fig. 5. The main difference of the four kinds is the extent of shotcrete damage on the failure face due to the shear behavior. Figure 5a shows that the failure face is the same as the original shotcrete-rock interface and there is no damage to the

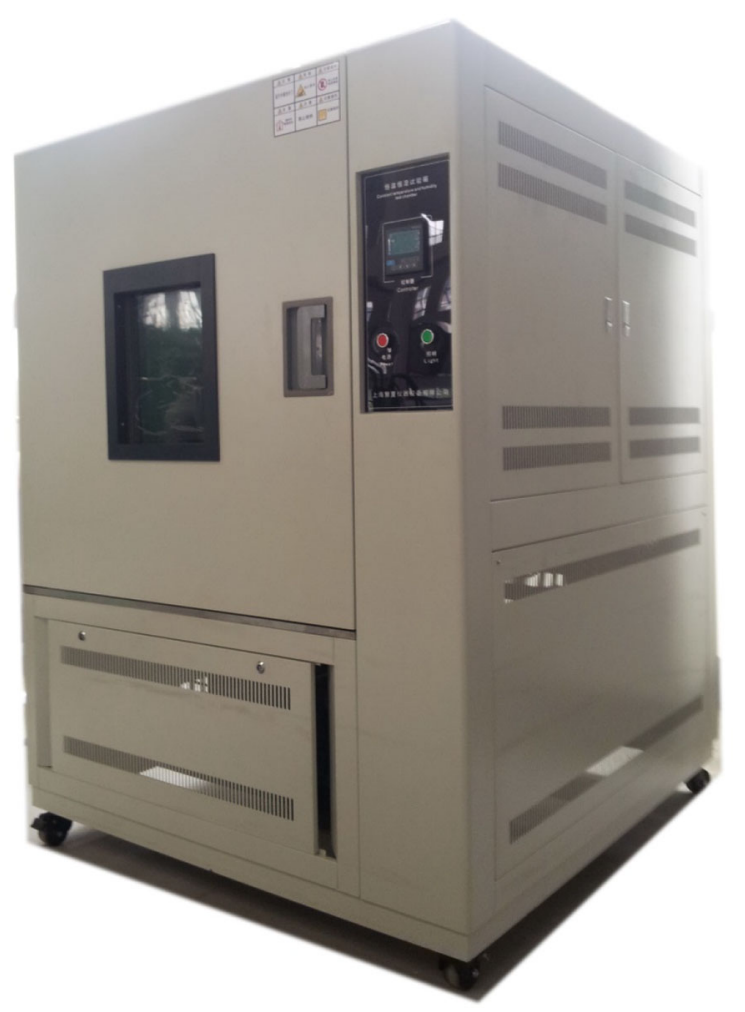

Fig. 3 Specimen curing device

shotcrete or granite. The shear failure occurred on the original shotcrete-rock interface on the whole in Fig. 5b. Some parts of the shotcrete face were destroyed by the shear force, which led to a number of concrete powers or articles remaining on the granite face. Compared with Fig. 5b, more damage to the shotcrete can be found in Fig. 5c. There are a plenty of abrasion marks on the whole shotcrete face and the remaining concrete powers or articles distribute all over the granite face. The interface representing the most serious damage to the shotcrete is shown in Fig. 5d. A large piece of shotcrete was stripped by the shear force and adhered to the granite face. So the failure face in Fig. $5 d$ was much rougher than those in Fig. 5a-c. 
Table 3 Parameters and their ranges used in the laboratory tests

\begin{tabular}{lll}
\hline Parameters & Variable temperature curing & Standard curing \\
\hline Initial curing temperature $\left({ }^{\circ} \mathrm{C}\right)$ & $40,60,80,100$ & 20 \\
Curing relative humidity $(\%)$ & 55,95 & 95 \\
Normal stress $(\mathrm{MPa})$ & $0.5,1.0,1.5$ & $0.5,1.0,1.5$ \\
\hline
\end{tabular}

Fig. 4 Shear test apparatus used in this study

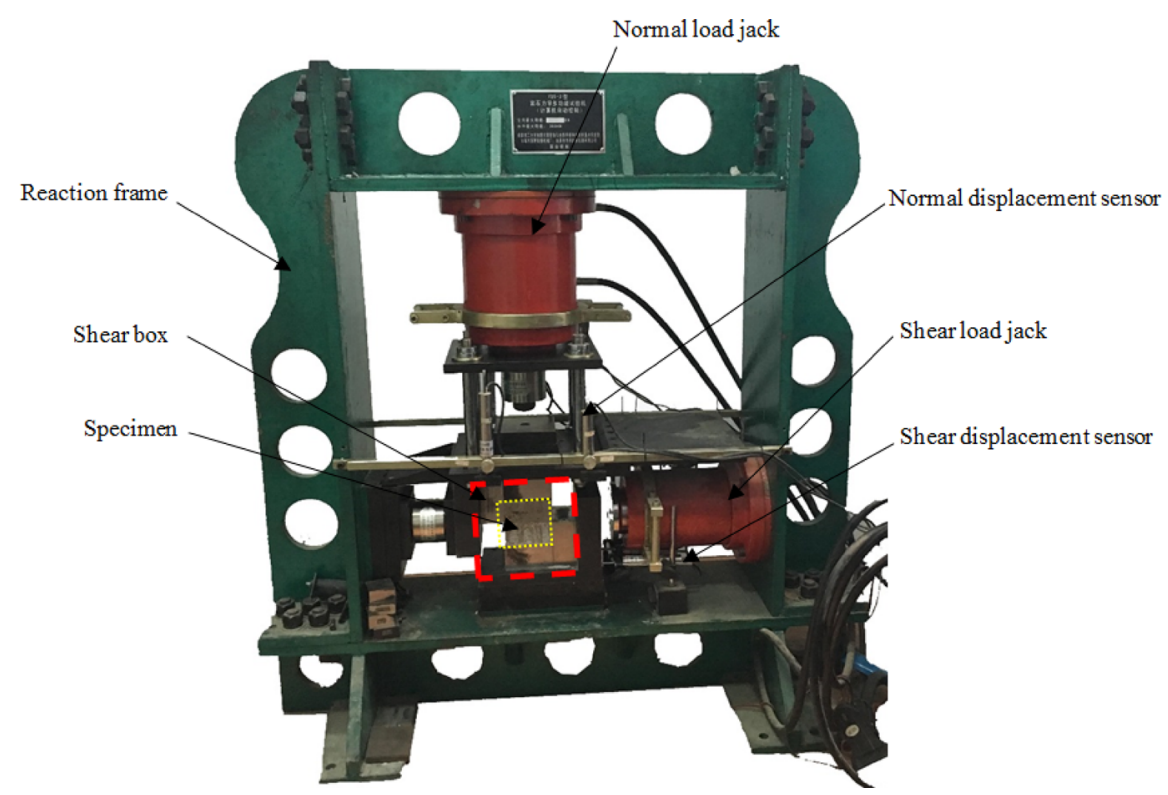

Under the curing environment of high temperature and relative humidity, the mechanical characteristics of shotcrete and shotcrete-granite interface are clearly influenced, however, that of granite are nearly unchanged. Then only the damage to the shotcrete on the failure face can be observed in the specimens. When the shear strength of the shotcrete is higher than that of the shotcrete-rock interface, the failure face may present the shape of Fig. 5a. When the shear strength of the shotcrete is rather lower than that of the shotcrete-rock interface, the failure face may show the appearance of Fig. 5d.

\section{Evaluation of the results}

\subsection{Peak shear strength of shotcrete-rock interface}

Figure 6 presents the results obtained from samples with VTC and SC. The shear stress increases firstly and then drops with the continuous increasing of curing temperature in all of cases shown from Fig. 6a$\mathrm{d}$. There is a trend in VTC tests that the peak shear stresses are corresponding to different curing temperature in the condition of different curing relative humidity. More specifically, the shear stresses reached the peak value when the curing temperature increased to $60{ }^{\circ} \mathrm{C}$ in the case of $55 \%$ relative humidity, while when the curing temperature increased to $80{ }^{\circ} \mathrm{C}$ in the case of $95 \%$ relative humidity. Cui et al. (2015) reported the similar observations that the bond strength of shotcrete-rock interface at $35{ }^{\circ} \mathrm{C}$ is higher compared with that at standard curing conditions $\left(20^{\circ} \mathrm{C}\right)$, while decreases when the temperature rises (especially at $70{ }^{\circ} \mathrm{C}$ ). By the microscopic research (He et al. 2013; Tang et al. 2015; Cui et al. 2015), when the curing temperature rises, the hydration of shotcrete will be accelerated, and more hydration products will rapidly fill in the shotcrete-rock interface which make its bond stronger. However, if the curing temperature is too high, the hydration speed is so high that its 
Fig. 5 Typical failure faces: $\mathbf{a}, \mathbf{b}, \mathbf{c}$ and $\mathbf{d}$ represent four kinds of failure faces which roughness increases from (a) to (d)
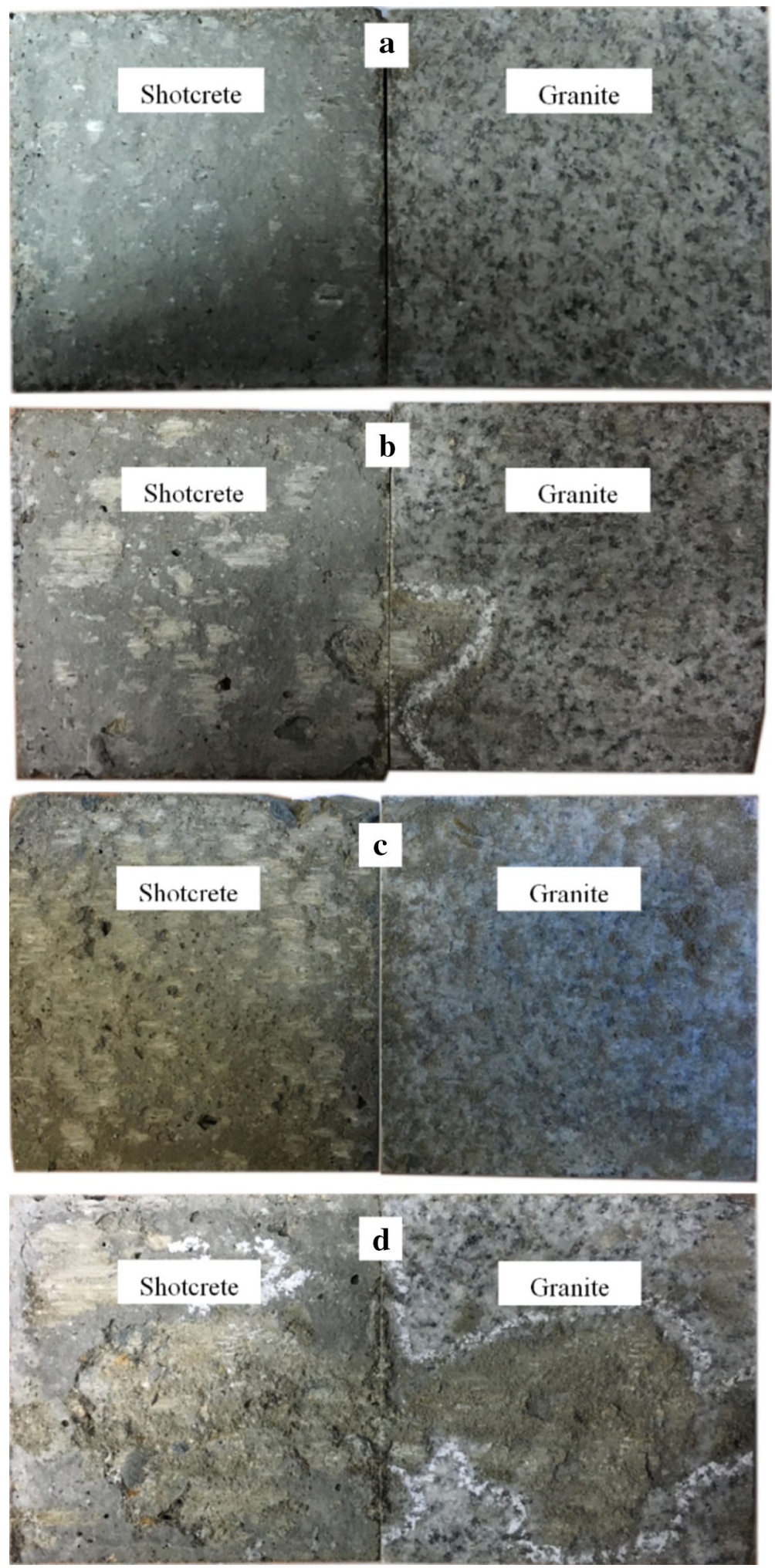
Fig. 6 The peak shear stress variations with curing temperatures: a C25, $55 \%$ $\mathrm{RH} ; \mathbf{b} \mathrm{C} 30,55 \% \mathrm{RH}$; c C25, $95 \%$ RH; d C30, $95 \% \mathrm{RH}$
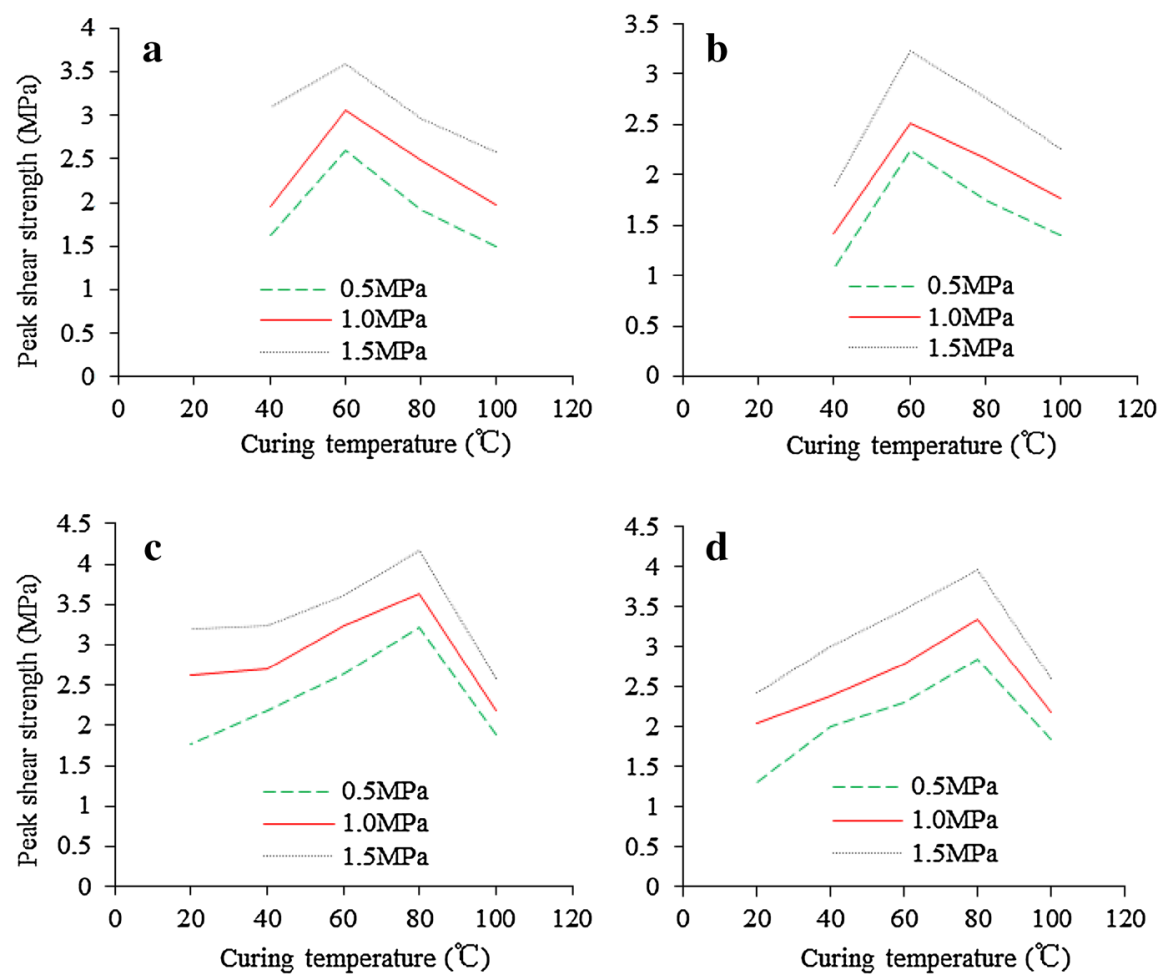

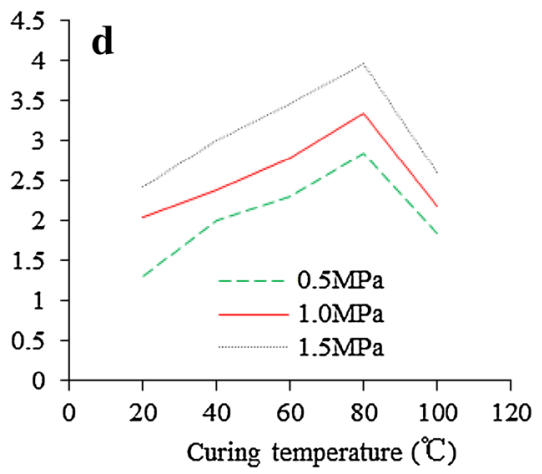

products cannot move quickly and array closely, which results in looser and porous microstructure of interface. Also, more cement particles are wrapped by the products and cannot take part in the later hydration because of higher temperature, which reduces the bond strength and shear strength of shotcrete-rock interface. When the curing relative humidity is $95 \%$, compared with the relative humidity of $55 \%$, the shotcrete loses less water under the effect of high temperature and more hydration products form. So the maximum of the peak shear strength of shotcrete-rock interface at the relative humidity of $95 \%$ occurred at the temperature of $80{ }^{\circ} \mathrm{C}$, while at the temperature of $60{ }^{\circ} \mathrm{C}$ when the relative humidity was $55 \%$.

It was also observed from Fig. 6c, $d$ that the peak shear stresses of SC tests with $95 \%$ relative humidity were higher than those of VTC tests with $100{ }^{\circ} \mathrm{C}$ curing temperatures and lower than those of VTC tests with $40,60,80^{\circ} \mathrm{C}$ curing temperatures. Figure 6 shows that the higher the normal stress is, the higher the peak shear stress is no matter what the curing temperature and relative humidity are. By comparing Fig. 6a and c, or b and d, a conclusion can be drawn that the peak shear stress is always increasing with the increasing of curing relative humidity, no matter how different the shotcrete strength, normal stress and curing temperature. The peak shear stress has the same varying tend to the shotcrete strength by comparing Fig. $6 \mathrm{a}$ and $\mathrm{b}$, or $\mathrm{c}$ and $\mathrm{d}$.

\subsection{Residual shear strength of shotcrete-rock interfaces}

The residual shear strength is increasing with the increase of normal stress, however, it is not critically influenced by curing temperature or relative humidity (see Fig. 7). As the environmental factors of shotcrete curing, temperature and humidity affect the shear behavior of shotcrete-rock interface by an indirect way of changing the concrete hydration speed and degree. Then there is a close relation between curing temperature or humidity and shotcrete strength or bond behavior of shotcrete-rock interface. The peak shear strength depends on the bond characteristics of shotcrete-rock interface, then is greatly affected by curing temperature and relative humidity. Because the failure face of shotcrete-rock interface occurs, shotcrete is no longer bonded to rock in the sample. Therefore, the residual shear strength of shotcreterock interface is closely linked to the interface 
Fig. 7 The residual shear strength variation with curing temperature: a $\mathrm{C} 25$, $55 \% \mathrm{RH} ; \mathbf{b} \mathrm{C} 30,55 \% \mathrm{RH}$ c C25, $95 \%$ RH; d C30, $95 \% \mathrm{RH}$
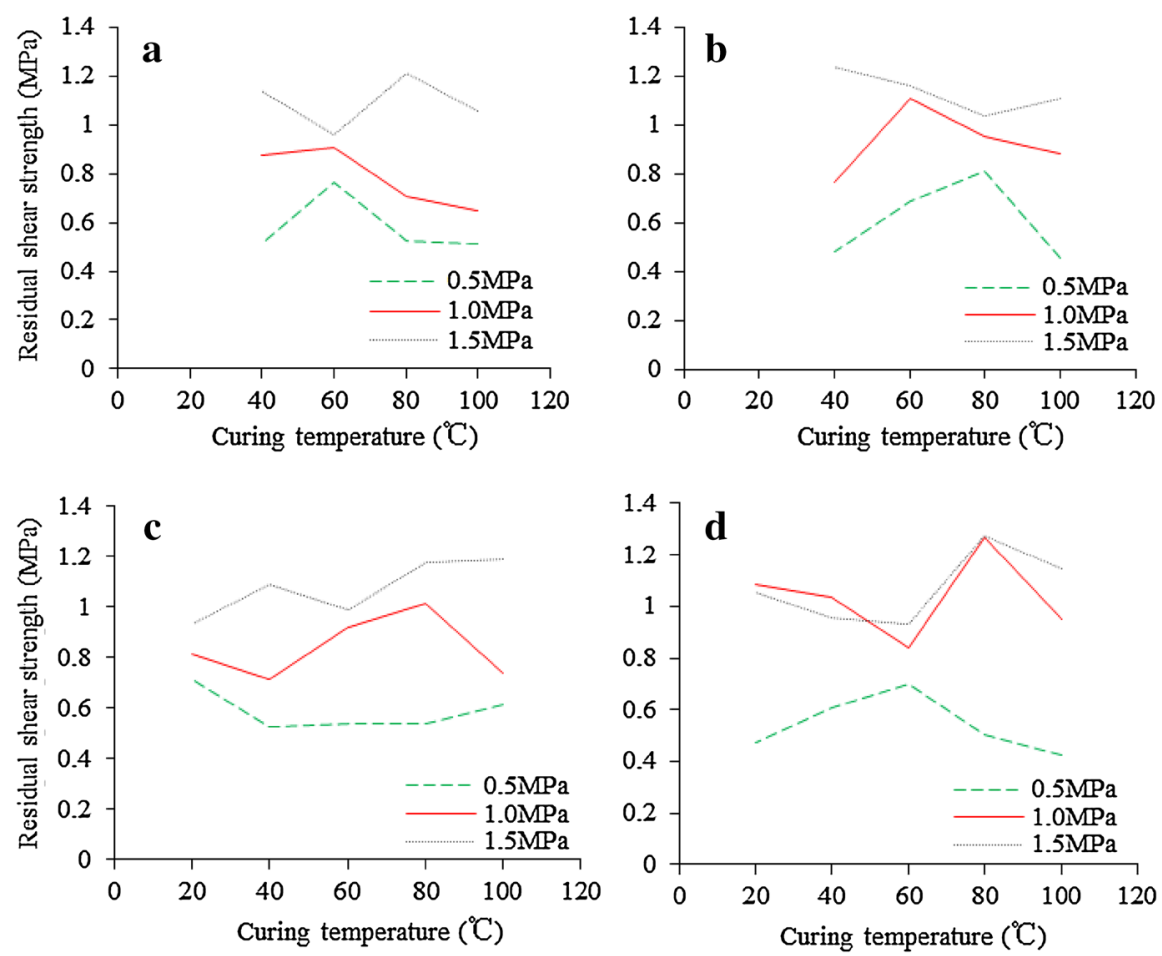

roughness and normal stress, not to curing temperature and relative humidity.

\subsection{Shear strength parameters of shotcrete-rock interface}

Figure 8a shows the similar results shown in Fig. 6. The peak cohesion increases firstly and then drops with the increasing of curing temperature. The cohesion reached the peak values when the curing temperature reaches to $60{ }^{\circ} \mathrm{C}$ with $55 \%$ relative humidity. However, the peak cohesion is observed when the curing temperature is raised to $80{ }^{\circ} \mathrm{C}$ with $95 \%$ relative humidity. It was also observed that the peak cohesions of SC tests with $95 \%$ relative humidity were higher than that of VTC tests with all curing temperatures. The higher the normal stress is, the higher the peak cohesion is. According to Fig. 8b, the peak friction angle is not seriously affected by curing temperature or relative humidity, as same as the residual cohesion and friction angle as shown in Fig. 8c, d. The curing temperature and humidity have a significant effect on the bond characteristics and the peak shear strength of the shotcrete-rock interface but not on the friction characteristics and the residual shear strength.
3.4 Relationship between shear stress and shear displacement

Four types of shear stress-displacement curve are shown in Fig. 9, which have the similar trends between shear stress and shear displacement in the section of pre-peak but reflect many differences in post-peak region. A sudden drop after peak was clearly revealed in Fig. 9a while the curve was gradually varying after peak in Fig. 9d. As the transition of (a) and (d), both sudden drop and gradual changing are showed in Fig. 9b or c, and the difference between Fig. $9 \mathrm{~b}$ and $\mathrm{c}$ is that the shear stress-displacement curve after peak shows greater sudden drop in Fig. $9 \mathrm{~b}$ and more noticeable gradual changing in Fig. 9c.

It can be found that the shear stress-displacement curve is the same to Fig. 9a when the sample has good bond and is under low normal stress $(<1.0 \mathrm{MPa})$, while that is the same to Fig. 9d when the sample has good bond and is under high normal stress $(>1.0 \mathrm{MPa})$, or its bond is poor. The similar observations were made by Swedenborg (2001), Saiang et al. (2005) and Tian et al. (2015). However, there is an interesting phenomenon that the shear stress-displacement curves are almost the same to Fig. 9a when their peak shear stresses are higher than 4.0 MPa, while 
Fig. 8 The variation of shear strength parameters with curing temperature: a peak cohesion; b peak friction angle; c residual cohesion; $\mathbf{d}$ residual friction angle
Fig. 9 Four types of shear behavior corresponding to various bond characteristics
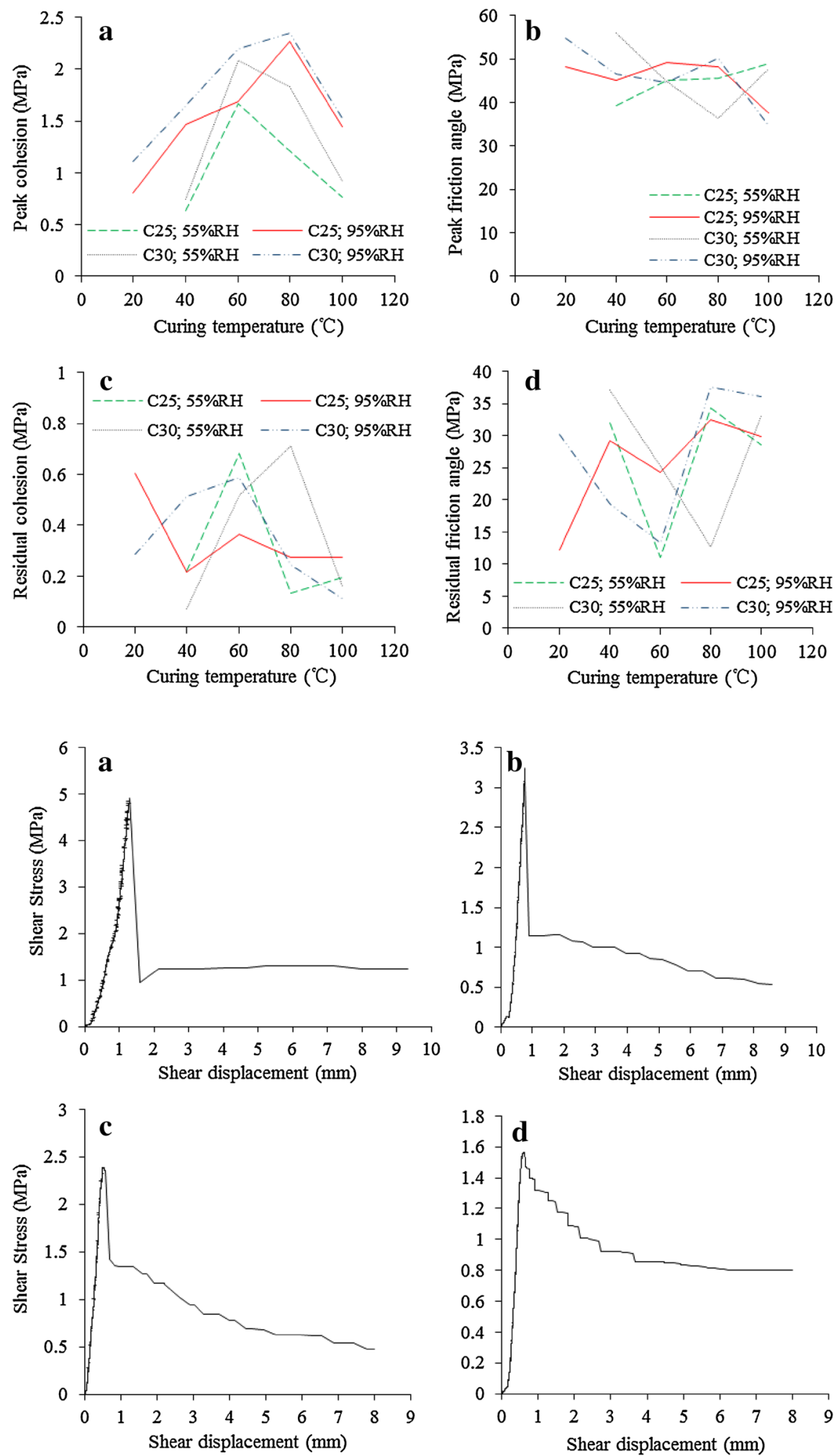
Fig. 10 Shear stressdisplacement curves: a C25, $95 \% \mathrm{RH}, 1.5 \mathrm{MPa}$; b C25, $40{ }^{\circ} \mathrm{C}, 55 \% \mathrm{RH}$
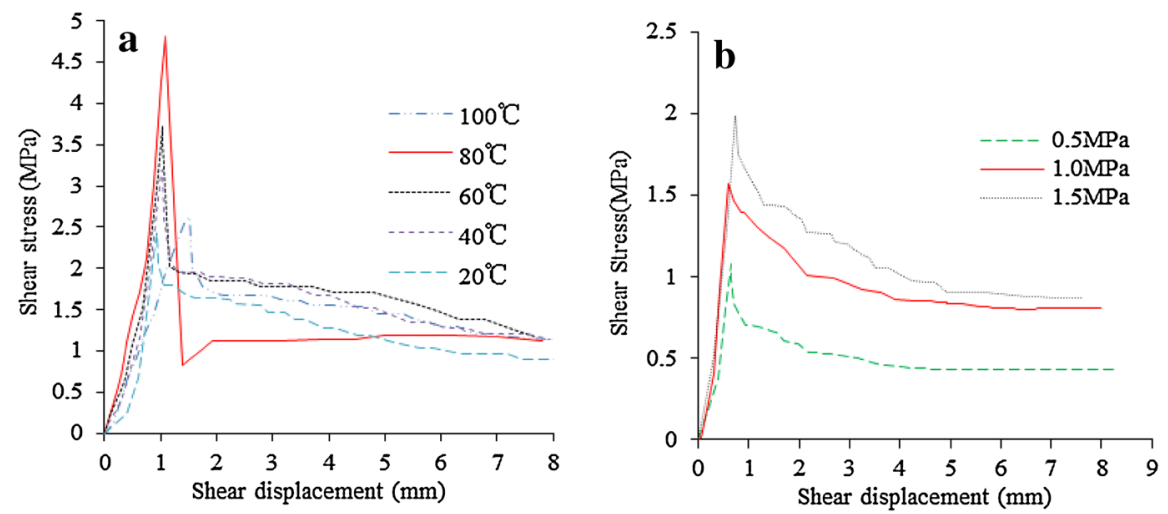

those are the same to Fig. $9 \mathrm{~d}$ when their peak shear stresses are lower than 1.5 MPa, no matter what the normal stresses are. Therefore, a conclusion may be drawn that the shape of shear stress-displacement curve is mainly influenced by both bond characteristics and normal stress when the bond strength is medium, while it is affected only by bond characteristics when the bond strength is much better or poorer.

Figure 10a shows five shear stress-displacement curves which have the same curing relative humidity, normal stress and shotcrete strength, and different curing temperature. The curve of $80{ }^{\circ} \mathrm{C}$ presents the kind of Fig. 9a. The curves of $60{ }^{\circ} \mathrm{C}$ and $40{ }^{\circ} \mathrm{C}$ present the kind of Fig. 9b. The curves of $100{ }^{\circ} \mathrm{C}$ and $20{ }^{\circ} \mathrm{C}$ present the kind of Fig. 9c. The same conclusion as Fig. 6c shown can be obtained that the peak shear stress increases with the increasing of temperature and reaches the maximum value at $80{ }^{\circ} \mathrm{C}$. The residual shear strengths in five temperatures have a little difference and seem not to be close relation with curing temperature and relative humidity.

Figure $10 \mathrm{~b}$ shows three shear stress-displacement curves which have the same curing temperature, relative humidity and shotcrete strength, and different normal stress. These curves belong to the kind of Fig. 9d. As same as the result from Fig. 6, the peak shear strength rises with the increasing of normal stress. By comparing the curve of $1.5 \mathrm{MPa}$ normal stress in Fig. 10b and that of $40{ }^{\circ} \mathrm{C}$ in Fig. 10a, the result can be obtained that higher the curing relative humidity value is, higher the peak shear strength is. And their residual shear strengths have a little difference. That means that the curing $\mathrm{RH}$ has no significant effect on the residual shear strength.

\section{Conclusions}

This paper investigates the effects of high temperature on the shear strength characteristics of shotcrete-rock interface for high rock temperature tunnels. A series of direct shear tests were conducted; the peak and residual shear strengths, shear strength parameters under various normal stress conditions ( $\left.\sigma_{n}=0.5-1.5 \mathrm{MPa}\right)$, the temperature ranges of $20-100{ }^{\circ} \mathrm{C}$ and the relative humidity of 55 and $95 \%$ were investigated. The shear stress-displacement characteristics of the failure faces were also examined. A special specimen curing method, Variable Temperature Curing, which was consistent with the field circumstances for high temperature tunnel cases was also introduced.

All of the curing temperatures, relative humidity and normal stress have significant impacts on the peak shear strength and peak cohesion of the shotcrete-rock interface. The peak shear strength, similar to the peak cohesion, increases firstly and drops with the increase of curing temperature, and reaches its maximum value at $60{ }^{\circ} \mathrm{C}$ and at $80{ }^{\circ} \mathrm{C}$ with the relative humidity of 55 and $99 \%$, respectively. The higher relative humidity caused higher peak shear strength and peak cohesion.

The curing temperature and relative humidity have close relations with the bond characteristics of shotcrete-rock interface, however, they seem to not to affected by the friction characteristics of shotcreterock interface. Only the normal stress is noticeably influenced by the residual shear strength. However, there are no strong correlations between the peak friction angle, residual cohesion and residual friction angle with the curing temperature and relative humidity found in our experiments. 
The shotcrete-rock failure at the interface showed four different types of damages. When the shotcrete shear strength is lower than that of the shotcrete-rock interface, the more damage at the interface was occurred.

Acknowledgments The authors gratefully acknowledge the support of the National Natural Science Foundation of China (Grant No. 51578458) and the Specialized Research Fund for the Doctoral Program of Higher Education of China (Grant No. 20130184110008).

\section{References}

Bae GJ, Chang SH, Lee SW, Park HG (2004) Evaluation of interfacial properties between rock mass and shotcrete. Int J Rock Mech Min Sci 41(3):373

Cui S, Zhu B, Li F, Ye Y (2015) Experimental study on bond performance between shotcrete and rock in a hot and humid tunnel environment. KSCE Journal of Civ Eng 20(4):1385-1391

General Administration of Quality Supervision, Inspection and Quarantine of the Peoples's Republic of China (AQSIQ), Standardization Administration of the People's Republic of China (SA) (2007) Common Portland cement (GB 175-2007). Beijing, China, November 9th, 2007

Gu BS (2015) Countermeasures against high temperatures in a tunnel and the corresponding ventilation design-feast ility study for the super-long Gaoligongshan tunnel. Mod Tunn Technol 44(2):66-71

Gu XF, Seidel JP, Haberfield CM (2003) Direct shear test of sandstone-concrete joints. Int J Geomech 3(1):21-33

He TS, Ji JT, Wang Y, Su XF (2013) Influence of mineral admixture on mechanical properties in high temperature surrounding rock tunnel. Mater Rev 6:119-122

Hochstein MP, Prebble WM (2006) Major engineering constructions on top of a high-temperature geothermal system: problems encountered at Tokaanu, New Zealand. Geothermics 35(4):428-447

Hou DP, Liu NF, Yu CH, Li N (2013) Discussion on design and construction measures for a rock tunnel in high-temperature conditions. Chin J Rock Mech Eng 32(S2):3396-3404

Johnston IW, Lam TSK (1984) Frictional characteristics of planar concrete-rock interfaces under constant normal stiffness conditions. Proceedings 4th Australia-New Zealand Conference on Geomechanics, Perth, Western Australia, 14-18 May 1984 V2, Publ. Barton: Inst of Engineers, pp 397-401

Karakus M, Liu Y, Zhang G, Tang H (2016) A new shear strength model incorporating influence of infill materials for rock joints. Geomech Geophys Geo-energy Geo-res 2(3):183-193

Kodikara JK, Johnston IW (1994) Shear behaviour of irregular triangular rock-concrete joints. Int J Rock Mech Min Sci Geomech Abstr 31(4):313-322

Lam TS, Johnston IW (1989) Shear behavior of regular triangular concrete/rock joints-evaluation. J Geotech Eng 115(5):728-740

Liu BJ, Xie YJ, Zhou SQ, Li J (2001) Some factors affecting early compressive strength of steam-curing concrete with ultrafine fly ash. Cem Concr Res 31(10):1455-1458
Ma QJ, Duan Y, Su H, Tang Y, Wang J, Li X, Ma CH (2015) Analysis on impacts of different rock wall temperatures on bonding strength between surrounding rock and shotcrete. Water Res Hydropower Eng 46(9):62-65

Malmgren L, Nordlund E (2008) Interaction of shotcrete with rock and rock bolts-a numerical study. Int J Rock Mech Min Sci 45(4):538-553

Ministry of Housing and Urban-Rural Development of the People's Republic of China (MHURD) (2003) Standard for test method of mechanical properties on ordinary concrete (GB/T 50081-2002). Beijing, China, April 1st, 2003

Ministry of Housing and Urban-Rural Development of the People's Republic of China (MHURD) (2015) Technical code for engineering of ground anchorages and shotcrete support (GB 50086-2015). Beijing, China, May 5th, 2015

Ooi LH, Carter JP (1987) Direct shear behaviour of concretesandstone interfaces. Proceedings of the 6th International Congress on Rock Mechanics, Montreal, Canada, 30 August-3 September, 1987, pp 467-470

Ou ZH (2011) The study of shotcrete performance and construction technology in hot environment (Master's thesis, Southwest Jiaotong University)

Paul M, Glasser FP (2000) Impact of prolonged warm $\left(85^{\circ} \mathrm{C}\right)$ moist cure on portland cement paste. Cem Concr Res 30(12):1869-1877

Saiang D, Malmgren L, Nordlund E (2005) Laboratory tests on shotcrete-rock joints in direct shear, tension and compression. Rock Mech Rock Eng 38(4):275-297

Seidel JP, Haberfield CM (2002) Laboratory testing of concreterock joints in constant normal stiffness direct shear. ASTM Geotech Test J 25(4):391-404

Swedenborg S (2001) Rock mechanical effects of cement grouting in hard rock. PhD Dissertation, Chalmers University of Technology, Sweden

Tang Y, Su H, Zhang H, Ma QJ, Jiang T (2015) Cohesive strength and micro failure mechanism of high geothermal diversion tunnel shotcrete surrounding rock. Water Res Power 33(4):127-129+63

Tannant DD, Wang C (2004) Thin tunnel liners modelled with particle flow code. Eng Comput 21(2/3/4):318-342

Tian HM, Chen WZ, Yang DS, Yang JP (2015) Experimental and numerical analysis of the shear behaviour of cemented concrete-rock joints. Rock Mech Rock Eng 48(1):213-222

Wang Y, He TS, Cheng L, Su XF (2015) Effect of mineral admixtures on properties of lining concrete under hightemperature rock wall condition. J China Railway Soc 37(2):118-124

Wang MN, Tang XH, Wu QJ, Tong JJ, Dong CY (2016) Temperature field variation rules of rock and support structure in high rock temperature tunnel. J China Railway Soc 38(11)(in print). www.tdxb.org

Wilhelm J, Rybach L (2003) The geothermal potential of Swiss Alpine tunnels. Geothermics 32(4):557-568

Xie JT, Yu YY (2013) Grades for heat damage in high altitude tunnel engineering. J Railway Eng Soc 12:69-73

Zhang G, Karakus M, Tang H, Ge Y, Zhang L (2014) A new method estimating the $2 \mathrm{D}$ joint roughness coefficient for discontinuity surfaces in rock masses. Int J Rock Mech Min Sci 72:191-198 